DOI: 10.35784/IAPGOS.238

\title{
ANALYSIS OF SOIL ORGANIC MATTER TRANSFORMATION DYNAMICS MODELS
}

\author{
Liubov Shostak, Mykhailo Boiko, Olha Stepanchenko, Olena Kozhushko \\ National University of Water and Environmental Engineering, Department of Applied Mathematics, Rivne, Ukraine
}

Abstract. In this paper we consider the models describing the dynamics of soil organic matter transformation. The results of practical implementation of the ROMUL, CENTURY and ROTHAMSTED models are presented. These models propose theoretical approaches to the modelling of organic remains transformation based on describing physicochemical processes during humus formation with differential relations. Following the analysis, their strengths and weaknesses have been distinguished.

Keywords: model, mineralization, soil organic matter, humus formation, soil

\section{ANALIZA MODELI DYNAMIKI TRANSFORMACJI MATERII ORGANICZNEJ GLEBY}

Streszczenie. W tym artykule rozważamy modele opisujace dynamikę transformacji materii organicznej $w$ glebie. Przedstawiono wyniki praktycznej realizacji modeli ROMUL, CENTURY i ROTHAMSTED. Modele te proponuja teoretyczne podejścia do modelowania transformacji szczątków organicznych oparte na opisie procesów fizykochemicznych podczas formowania się próchnicy z zależnościami różnicowymi. W wyniku analizy wyróżniono ich mocne i stabe strony.

Slowa kluczowe: model, mineralizacja, materia organiczna gleby, tworzenie się próchnicy, gleba

\section{Introduction}

Soil is one of the most fundamental parts of the earth's ecosystem. It carries out unique functions in the turnover of biological elements. Specifically, in the soil the organic matter of dead organisms and their lifelong excretions is mineralized. Part of organic substance settles in the soil as humus, which ensures the sustainability of ecosystem and facilitates its renewal after natural and artificial disruptions. Therefore, the study of organic matter formation in the soil is a priority issue of dynamical soil systems modelling. Model of dynamical soil organic matter formation can be logically included into other ecosystem model as a basic component. It should be noted that the majority of existing ecosystem models do not consider soil processes that govern the productivity of photosynthetic organisms by reactive coupling of nutritive compounds incoming from the soil and physical environment optimization [4].

Soil is a highly complex object for modelling. It is quite difficult to describe adequately all dynamical processes taking place in the soil and determine relations between the coefficients of organic matter transformation. Two principal processes occurring in the soil can be distinguished: soil organic matter mineralization and it humification. Transformation of organic remains is occurring by the means of microorganisms, reductionoxidation processes, destruction, mineralization, hydrolysis and humification of organic matter.

Most of the models describing the transformation of organic remains differ by the ways of considering different organic profiles, representation of certain types of destructor organisms, and different transformation processes.

Modelling of organic matter formation in the soil is usually conducted in one of the two approaches. The first approach represents soil as a mixture of different organic compounds, where the transformation of organic remains depends on temperature, moisture and acidity degree. The well-known models realized in computer programs are ROMUL[2] and CENTURY[9]. Another approach does not separate organic remains into components, and is based on the integral description of the transformation. In this case, an essential role is played by the microorganisms destructors of the organic matter. Their activity depends on the dynamics of nutritive compounds, especially on the nitrogen content in the soil (e.g. ROTHAMSTED model) [6].

The developed models are adequately imitating the soil system functioning. Although there exists a great number of soil dynamics models, they still require further theoretical justification, improvement of model structure, preparation and arranging of input data.

\section{The ROMUL model (model of Raw humus, mOder, and MULI)}

The model allows to calculate dynamics of soil organic matter formation and the quantity of mineral nitrogen. It is assumed in the model, that the litter can be separated into various cohorts characterized by a particular position in the soil, ash, and nitrogen content.

Principal organic matter destruction and mineralization processes are related to the vital activities of microorganisms, that are forming distinct types of humus (mor, moder and mull) on each level.

The general assumption on the model involves the sequence of correlated changes in destructor organisms during the decay of organic matter. Quantity and species composition of destructor organisms depend on biochemical properties of leaf litter, hydrological and heat conditions. The rate of nutrients release due to mineralization corresponds to the rate of organic matter mineralization. The model assumes destructor organisms spend $20 \%$ of nitrogen on the complex of humic compounds, and $80 \%$ on the humus formation.

The process of complex organic matter mineralization in the soil layers can be described by the following system of differential equations:

$$
\begin{gathered}
\frac{d L^{i}}{d t}=L_{0}^{i}-\left(k_{1 L}^{i}+k_{3 L}^{i}\right) L^{i}, \\
\frac{d N_{L}^{i}}{d t}=N_{L 0}^{i}-\left(k_{1 L}^{i} M_{L}^{i}+k_{3 L}^{i}\right) N_{L}^{i}, \\
\frac{d L_{u}^{j}}{d t}=L_{u 0}^{j}-\left(k_{1 S}^{j}+k_{3 S}^{j}\right) L_{u}^{j}, \\
\frac{d N_{L u}^{j}}{d t}=N_{L u 0}^{j}-\left(k_{1 S}^{j} M_{L}^{j}+k_{3 S}^{i}\right) N_{L u}^{j}, \\
\frac{d F^{i}}{d t}=k_{3 L}^{i} L^{i}-\left(k_{2 L}^{i}+k_{4 L}^{i}+k_{5 S}^{i}\right) F^{i}, \\
\frac{d F_{u}^{j}}{d t}=k_{3 S}^{i} L_{u}^{j}-\left(k_{2 S}^{j}(H) M_{F u}^{i}-\left(k_{2 L}^{i} M_{F}^{i}\left(F^{i}, N_{F}^{i}\right)+k_{4 L}^{i}+k_{5 S}^{i}\right) N_{F}^{i},\right. \\
\left.\frac{d H}{d t}=\delta_{B a c t}\left(\sum_{i=1}^{m} k_{4 L}^{i} N_{F}^{i}+\sum_{j=1}^{n} k_{4 S}^{j} N_{F u}^{j}\right)+k_{4 S}^{j}+k_{5 S}^{j}\right) N_{F u}^{j}, \\
+\delta_{L u m b}\left(\sum_{i=1}^{m} k_{5 S}^{i} N_{F}^{i}+\sum_{j=1}^{n} k_{5 S}^{j} N_{F u}^{j}\right)-k_{6} H,
\end{gathered}
$$




$$
\begin{gathered}
\frac{d N_{H}}{d t}=\gamma\left(\sum_{i=1}^{m}\left(k_{4 L}^{i}+k_{5 S}^{i}\right) N_{F}^{i}+\sum_{j=1}^{n}\left(k_{4 S}^{j}+k_{5 S}^{j}\right) N_{F u}^{i}\right)- \\
-k_{6} M_{H}\left(H, N_{H}\right) N_{H} .
\end{gathered}
$$

In the above equations upper index $i$ signifies $i^{\text {th }}$ cohort of belowground litter, $j-j^{\text {th }}$ cohort of belowground organic remains; $L$ and $N_{L}$ - undecomposed organic remains and corresponding nitrogen content of the litter; $L_{0}$ and $N_{L 0}$-initial income of organic matter and nitrogen into the soil; $L_{u 0}$ i $N_{L u 0}-$ income of organic matter and nitrogen into the belowground soil litter; $L_{u}$ and $N_{L u}$ - litter that is not decomposed by the belowground cohorts; $F$ models the content of humic compounds in belowground soil layer; $k_{1 L}$ - the rate of aboveground litter mineralization by the soil destructors; $k_{1 S}$ - corresponding rate of belowground mineralization; $k_{2 L}$ - rate of aboveground humic complex mineralization; $k_{3 L}, k_{3 S}$ - transformation rate of humic compounds during organic matter humification; $k_{4 L}$ - rate coefficient of humic compounds consumption by Bacteria+Arthropoda community; $k_{5 s}$ - rate coefficient of humic compounds consumption by earthworm; $M_{L}-$ relative nitrogen mineralization index; $M_{F}$ - relative nitrogen mineralization rate in layer $F ; F u$ and $N_{F u}$ - humic compounds and nitrogen content in belowground layers of organic matter; $k_{2 S}(H)$ - rate of belowground humic complex mineralization in layer $H ; k_{4 S}-$ humic compounds consumption rate coefficient by Bacteria+Arthropoda community; $k_{2 s}$ - rate of belowground humic complex mineralization; $\delta_{\text {Bact }}, \delta_{\text {Lumb }}-$ coefficients representing nitrogen consumption for biomass destruction and humus formation; $N_{F}$ - humic compounds complex coming from aboveground cohorts and corresponds to nitrogen content in the soil; $N_{F u}, F u$ - humic compounds complex coming from belowground cohorts; $k_{6}$ - humus mineralization rate, $H$ and $N_{H}$ - completely humified matter (humus) and nitrogen content in the soil.

Equation (1) governs the transformation of undecomposed aboveground organic remains in the litter layer. Equation (2) describes the nitrogen formation in the litter layer. Equation (3) governs organic matter transformation in the layers that are not decomposed by belowground cohorts. Equation (4) governs nitrogen formation in the layers that are not decomposed by belowground cohorts. Equation (5) governs humic compounds content in the belowground soil layer. Equation (6) determines the quantity of humic compounds coming from aboveground cohorts and corresponds to nitrogen content in the soil. Equation (7) calculates the quantity of humic compounds coming from belowground cohorts. Equation (8) evaluates the quantity of completely humified matter (humus) that will be formed in the soil. Equation (9) determines nitrogen quantity that will be formed in the soil.

Values of $k_{i s}$ and $k_{i L}$ coefficients vary depending on nitrogen and ash content in the litter, temperature, and moisture. The model considers differences between organic remains decomposition by belowground and aboveground cohorts.

Linear dependencies of model coefficients on the ash and nitrogen content can be expressed by the equations [5]:

$$
\begin{gathered}
k_{1 L}=0.002+0.009 x_{1}+0.003 x_{2}, \\
k_{2 L}= \begin{cases}0.002 x_{2}, & x_{2} \leq 0.5 \%, \\
0.00114-0.00028 x_{2}, & x_{2}>0.5 \%,\end{cases} \\
k_{3 L}=\left\{\begin{array}{cc}
0.005 x_{1}, x_{1} \leq 2 \%, \\
0.04-0.003 x_{1}, 0.5 \% \leq x_{1} \leq 12 \%,
\end{array}\right. \\
k_{4 L}= \begin{cases}0.005 x_{2}, & x_{2} \leq 2 \%, \\
0.001, & x_{2}>2 \%\end{cases} \\
k_{5 S}^{\prime}= \begin{cases}0.2 x_{1}, & x_{1} \leq 5 \%, \\
k_{5}^{\prime}, & x_{1}>5 \%, \\
0.00462 x_{2}-0.00231, & 0.5 \%<x_{2}, \\
0.007, & 2 \%<x_{2}\end{cases} \\
k_{6}=0.00006,
\end{gathered}
$$

where $x_{1}$ is ash content in the soil, $x_{2}$ is nitrogen content in the soil.

In the ROMUL model, temperature and moisture dependence is considered in the form of correction to parameters $k_{i}$. It accounts for the temperature and moisture of organic matter decomposition.

The correctional coefficients are determined using the relations [5]:

$$
\begin{gathered}
k_{1 S}=1,6 k_{1 L}, \\
k_{2 S}(H)=k_{2 L}\left(1,22+0,488 H_{m}\right), \\
k_{3 S}=1,35 k_{3 L}, \\
k_{4 S}=k_{4 L},
\end{gathered}
$$

where $H_{m}$ is humus content in mineral soil horizon. Experimental data indicated [4], that mineral soil has influence over organic remains decomposition rate. On the other hand, soil texture does not impact belowground organic matter decomposition rate.

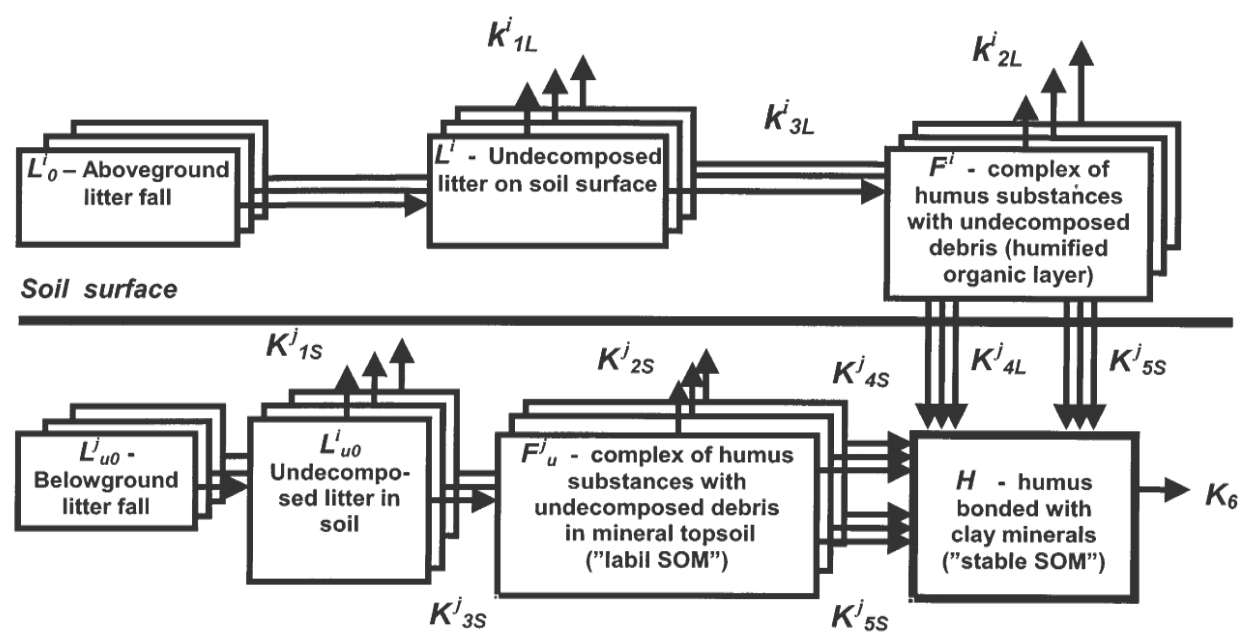


Relative nitrogen mineralization indices are determined as follows [5]:

$$
M_{N}= \begin{cases}0.1 M_{o v}, & x_{2}-1,16 x_{1} \leq 0.44, \\ 0.5 M_{o v}, & 0.44<x_{2}-1.16 x_{1} \geq 1.5, \\ 1.0 M_{o v}, & 1.5<x_{2}-1.16 x_{1},\end{cases}
$$

where $M_{N}$ is nitrogen mineralization rate, $M_{o v}$ is organic matter mineralization rate, $x_{1}$ - initial nitrogen content in undecomposed soil layer, $x_{2}-$ current nitrogen content in decomposed organic soil layer.

The quantity of mineralized humus and nitrogen available for plants is a substantial parameter in the ROMUL model. On each time step, the quantity of mineralized humus is calculated as

$$
\begin{gathered}
H_{\min e r}=k_{1 L} L+k_{1 S} L_{u}+\left(k_{2 L}+k_{4 L}+k_{5 S}\right) F+ \\
+\left(k_{2 S}+k_{4 S}+k_{5 S}\right) F_{u}-\delta_{\text {Bact }}\left(k_{4 L} N_{F}+k_{4 S} N_{F u}\right)- \\
-\delta_{\text {Lumb }}\left(k_{5 S} N_{F}+k_{5 S} N_{F u}\right)+k_{6} H .
\end{gathered}
$$

Nitrogen available for plants is determined as

$$
\begin{aligned}
N_{\text {avail }}= & k_{1 L} M_{L} N_{L}+k_{1 S} M_{L} N_{L u}+k_{2 L} M_{F} N_{F}+k_{2 S} M_{F u} N_{F u}+ \\
& \gamma\left(\left(k_{4 L}+k_{5 S}\right) N_{F}+\left(k_{4 S}+k_{5 S}\right) N_{F u}\right)+k_{6} M_{H} N_{H} .
\end{aligned}
$$

To evaluate soil moisture we use the following data: precipitation amount, air and soil temperature. As soil moisture data are difficult to find, we used balance equations to determine water content in the active soil layer:

$$
W=r-E-f,
$$

where $r$ is the amount of precipitation, $E$ - evapotranspiration, $f$ - total sink.

$$
\begin{aligned}
& \text { Evapotranspiration is determined as } \\
& E= \begin{cases}E_{0}, & \text { at } W>W_{0} \text { or } W^{(P)}>W_{0}^{(P)}, \\
E_{0} \frac{W^{(P)}}{W_{0}^{(P)}}=E_{0} \frac{W-W_{W P}}{W_{0}-W_{W P}} & \text { at } W<W_{0} \text { or } W^{(P)}<W_{0}^{(P)},\end{cases}
\end{aligned}
$$

where $W$ is moisture content in root zone, $W_{0}$ - critical value of $W, W^{(P)}=W-W_{W P}, W_{W P}-$ moisture content on wilting point.

Sink term is determined as

$$
f=\mu r \frac{W^{(P)}}{W_{k}^{(P)}}=\mu r \frac{W-W_{W P}}{W_{k}-W_{W P}} ;
$$

where

$$
\mu=\left\{\begin{array}{lll}
\alpha & \text { at } & r<E_{0}, \\
\sqrt{\alpha^{2}\left[1-\left(1-\frac{E_{0}}{r}\right)^{2}\right]+\left(1-\frac{E_{0}}{r}\right)^{2}} & \text { at } & r>E_{0}
\end{array},\right.
$$

$\alpha \approx 0.2$ is an empirical coefficient, calculated for the latitudes of $45^{\circ}$ and higher;

$$
W_{k}=\left\{\begin{array}{c}
W_{F C}-\text { field capacity (for } \\
\text { well drained soils), } \\
W_{S}-\text { full capacity (if groundwaters } \\
\text { are close to the surface). }
\end{array}\right.
$$

Using the given model we evaluated the quantity of organic matter that will be formed in the soil in 10 years for different soil types (Fig. 2). To do so we used soil moisture (soil moisture at the end of month, average within 0-1 m layer) and temperature data (monthly average soil temperature at $0.2 \mathrm{~m}$ depth), represented in Table 1.

The quantity of formed organic matter was calculated for the following soil types: mor sandy podzol, mor loamy gley-podzolic and loamy sand sod-podzolic. Initial organic matter quantity in mor sandy podzol $-5.47 \frac{\mathrm{kg}}{\mathrm{m}^{2} \text { year }}$, mor loamy gley-podzolic $1.52 \frac{\mathrm{kg}}{\mathrm{m}^{2} \text { year }}$, loamy sand sod-podzolic $-2.97 \frac{\mathrm{kg}}{\mathrm{m}^{2} \text { year }}$.

Based on input data, we calculated model correction coefficients that account for the influence of moisture and temperature on soil organic layer formation (Table 2).

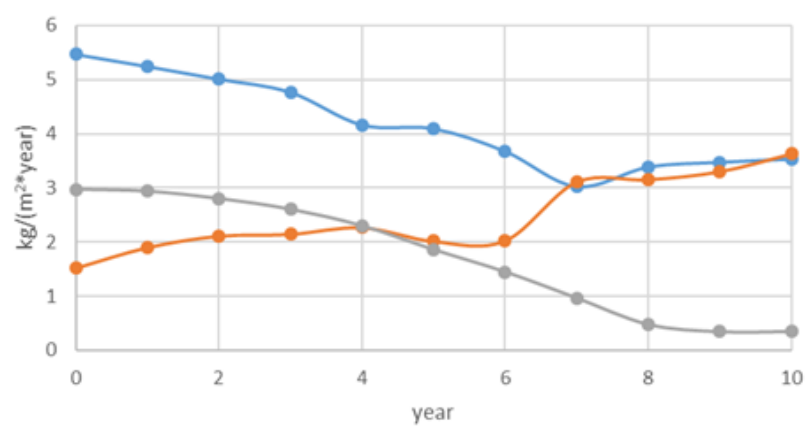

$\longrightarrow$ Mor sandy podzol $\longrightarrow \longrightarrow$ Mor loamy gley-podzolic $\longrightarrow$ Loamy sand sod-podzolic

Fig. 2. Quantities of organic matter that will be formed in the soil in 10 years for different soil types

Table 1. Monthly average soil moisture and temperature

\begin{tabular}{|c|c|c|}
\hline Month & $\begin{array}{c}\text { Moisture } \\
\text { (wt. \%) }\end{array}$ & Temperature $\left({ }^{\circ} \mathrm{C}\right)$ \\
\hline 1 & 17.25 & 0.23 \\
\hline 2 & 17.45 & 0.86 \\
\hline 3 & 18.05 & 0.86 \\
\hline 4 & 20.23 & 2.13 \\
\hline 5 & 18.05 & 7.17 \\
\hline 6 & 15.43 & 9.53 \\
\hline 7 & 14.01 & 13.23 \\
\hline 8 & 14.09 & 14.07 \\
\hline 9 & 15.13 & 15.12 \\
\hline 10 & 17.09 & 17.25 \\
\hline 11 & 17.35 & 17.55 \\
\hline 12 & 17.52 & 17.63 \\
\hline
\end{tabular}

Table 2. Correction coefficients

\begin{tabular}{|c|c|c|c|}
\hline Month & $a_{i 1}$ & $a_{i 2}$ & $a_{i 3}$ \\
\hline 1 & 0.189 & 0.58 & 0.004 \\
\hline 2 & 0.286 & 0.591 & 0.018 \\
\hline 3 & 0.302 & 0.625 & 0.019 \\
\hline 4 & 0.6 & 0.748 & 0.053 \\
\hline 5 & 1.289 & 0.496 & 0.161 \\
\hline 6 & 1.265 & 0.506 & 0.183 \\
\hline 7 & 1.42 & 0.587 & 0.231 \\
\hline 8 & 1.52 & 0.632 & 0.247 \\
\hline 9 & 1.864 & 0.779 & 0.285 \\
\hline 10 & 2.617 & 1.104 & 0.368 \\
\hline 11 & 2.728 & 1.153 & 0.38 \\
\hline 12 & 2.785 & 1.176 & 0.386 \\
\hline
\end{tabular}

The results indicate that quantity of formed organic matter is substantially influenced by the soil type, ash content, nitrogen content, soil moisture and temperature.

Two aspects of the model can be distinguished:

1) there is a clear influence of mineral soil layer over humic compounds decomposition, but no impact of the soil texture on decomposition rate is present;

2) Mineralization rate depends on soil granulometric composition.

The model can also be used for estimating carbon flow from the soil into the atmosphere due to mineralization of humic compounds.

Soil temperature is modelled based on Gaussian distribution, considering autocorrelation and correlation with air temperature. To determine evapotranspiration, authors used the Blaney and Criddle model [1], which allows to evaluate potential evapotranspiration based on the air temperature only. Soil organic matter is represented by three layers: surface litter, soil litter and organic matter of mineral soil horizons.

The ROMUL model enables to calculate a quite complex balance of organic matter, nitrogen and, potentially, other elements in forest soils by introducing separate organic matter layer cohorts, which clearly is its advantage. However, a weakness has been found while doing calculations according to the model methods. Mineralization rate, computed by the model, exceeds its rate in the natural conditions. 


\section{CENTURY model}

CENTURY is a model of soil biogeochemistry based on interrelations between climate, soil properties, crop productivity and decomposition of organic remains. The model considers carbon, nitrogen, phosphorus, and sulphur [9].

The organic remains are classified into: 1) fresh organic remains (surface litter) consisting of two parts: structural and metabolic; 2) "active" organic remains that comprise microbial biomass with 5-year complete mineralization time; 3) "slow" organic remains that are mineralized in less than 59 years; 4) "passive" organic remains that are mineralized in less than 1000 years.

In this model, lignin (plant material) fraction does not constitute microbial biomass and decomposes directly in the "slow" organic remains layer. It is accounted that $60 \%$ of carbon is spent on microbial breathing. State variables are calculated by the following equations:

$$
\begin{gathered}
\frac{d C_{l}}{d t}=K_{l} L_{c} A C_{l}, \quad I=1,2 \\
\frac{d C_{l}}{d t}=K_{l} A T_{m} C_{l}, \quad I=3 \\
\frac{d C_{l}}{d t}=K_{l} A C_{l}, \quad I=4,5,6,7,8 \\
T_{m}=(1-0.75 T), \\
L_{c}=e^{\left(-3 L_{s}\right)},
\end{gathered}
$$

where $C_{l}$ is carbon content in variable state $(I=1,2,3,4,5,6,7,8)$ in the aboveground and belowground soil layers; $K_{l}$ - maximum organic matter decomposition rate; $A-$ combined abiotic influence of soil temperature and moisture on organic matter decomposition; $L_{c}-$ influence of lignin content on structural remains decomposition; $T_{m}$ - soil texture influence on the amount of active organic remains; $T$ - silt and clay content in the soil; $L_{s}$ - structural material of organic remains.

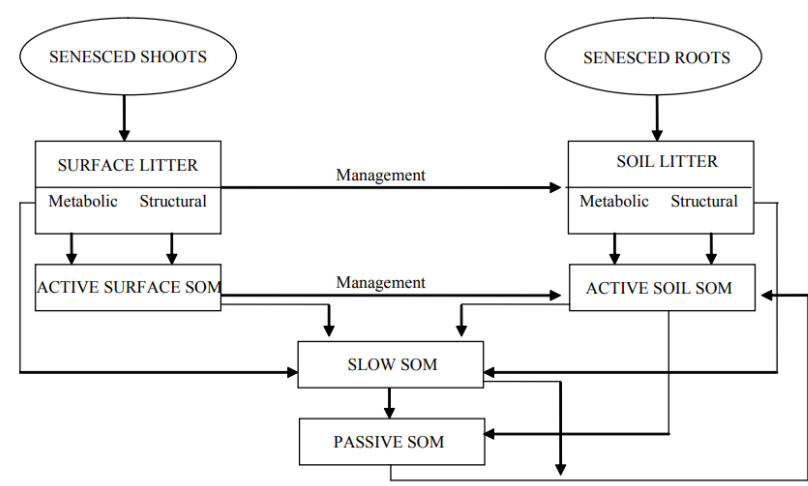

Fig. 3. Structure of CENTURY soil organic matter (SOM) model

CENTURY is a first order decomposition model, where metabolic and structural organic matter decomposition rates are corrected by the coefficients of soil temperature and moisture change. Transformation of organic remains in the soil layer is governed by the differential equation:

$$
\begin{aligned}
\frac{d C_{j}(t)}{d t}= & {\left[x_{M R, j} v_{M R}\right]+\left[x_{S R, j} v_{S R}\right]+\left[x_{A, j} v_{A}\right]+} \\
& +\left[x_{S, j} v_{S}\right]+\left[x_{P, j} v_{P}\right]-v_{j},
\end{aligned}
$$

where $x_{M R, j}$ is a fraction of recomposed carbon received from metabolic organic matter layer and is included into humic compounds complex; $v_{M R}$ - decomposition rate of metabolic organic matter layer; $x_{S R, j}-$ structural organic remains layer; $v_{S R}$ - decomposition rate of structural organic remains layer; $x_{A, j}-$ active organic remains layer; $v_{A}-$ decomposition rate of active organic remains layer; $x_{S, j}$ - slow organic remains layer; $v_{S}-$ decomposition rate of slow organic remains layer; $x_{P, j}$ - passive organic remains layer; $v_{P}$-decomposition rate of passive organic remains layer; $v_{j}$-decomposition rate of all organic remains.

Monthly organic matter decomposition rate is determined by the following relation:

$$
v_{j}(m)=k_{j}^{*}(m) \cdot C_{j}(m),
$$

where $k_{j}^{*}(m)$ is a decomposition rate coefficient of organic matter with respect to the corresponding soil layer $j$ that is taking into account soil temperature, moisture and texture variations; $C_{j}(m)$ is initial carbon content in the soil.

Also, the Crank-Nicolson method can be applied to determine organic matter decomposition rate using average values $C_{j}(m)$ and $C_{j}(m+1)$ :

$$
v_{j}(m)=k_{j}^{*}(m) \frac{C_{j}(m+1)+C_{j}(m)}{2},
$$

where $C_{j}(m+1)$ is current carbon content in the soil.

The quantity of humified organic carbon is determined using the following differential equation:

$$
\frac{d C_{i}}{d t}=S_{i}+\sum_{j \neq i}\left(1-r_{j}\right) f_{j i} k_{j} C_{j}-k_{i} C_{i},
$$

where $S_{i}$ is initial carbon content, $r_{j}$ - heterotrophic breathing rate coefficient, $f_{j i}-$ fraction transition from $j^{\text {th }}$ to $i^{\text {th }}$ layer; $k_{i}$ - moisture variation rate coefficient, $k_{j}$ - temperature variation rate coefficient.

Discretization yields the following differential equation:

$$
\begin{aligned}
\frac{d C_{i}(z)}{d t}=S_{i}(z)+ & \sum_{j \neq i}\left(\left(1-r_{j}\right) f_{j i} k_{j} C_{j}\right)(z)-k_{i}(z) C_{i}(z)+ \\
& +\frac{d}{d z}\left[D(z) \frac{d C_{i}(z)}{d z}\right],
\end{aligned}
$$

where $\frac{d}{d z}\left[D(z) \frac{d C_{i}(z)}{d z}\right]$ describes cryoturbation process.

All carbon decomposition streams are related to microbial activity. Mineralization rates depend on temperature and moisture. The model assumes that decaying plant litter forms active and passive layers. Regarding soil productivity, CENTURY uses the following statistical criterions: sample determination coefficient, normalized mean square error, index of agreement. The advantage of the model lies in the possibility to predict system behaviour and reaction to such manipulations as irrigation or changes in land use. The disadvantage is that the model does not include a function to account for the influence of acidity on plant growth. Thus, during testing it failed to simulate organic matter development in acidic grasslands.

\section{ROTHAMSTED model}

ROTHAMSTED is a model of calculating organic carbon content in arable topsoil. The model can also be used for longterm prediction of carbon content change due to climate change, calculating carbon loss rate or carbon sequestration in the agricultural soils. The model assumes organic remains consist of: 1) decomposable plant material; 2) resistant plant material; 3) microbial mass; 4) humified organic matter. For every soil layer, a constant of organic matter decomposition rate is set.

The organic remains transformation process is described by the equation:

$$
\left(\begin{array}{c}
D P M[(n+1) T] \\
R P M[(n+1) T] \\
B I O[(n+1) T] \\
H U M[(n+1) T]
\end{array}\right)=I\left(\begin{array}{c}
D P M[n T] \\
R P M[n T] \\
B I O[n T] \\
H U M[n T]
\end{array}\right)+\left(\begin{array}{c}
P_{d p m}[n T] \\
P_{r p m}[n T] \\
0 \\
0
\end{array}\right) .
$$


here $D P M$ is decomposable plant material, $R P M$ - resistant plant material that is decomposing slowly, $B I O$ - microbial biomass, $H U M$ - humified plant material, $T$ - data selection time, $P_{d p m}, P_{r p m}$ - initial information on organic matter content, $I-$ model transition matrix describing organic matter transformation in each soil compartment:

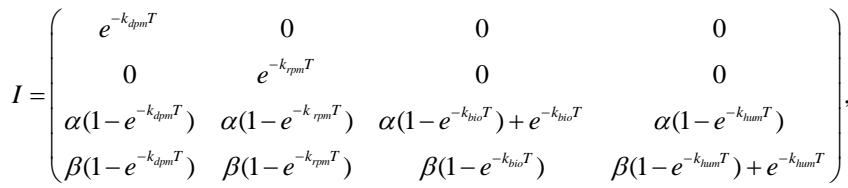

where $k_{d p m}, k_{r p m}, k_{b i o}$ and $k_{h u m}$ are experimental decomposition constants of corresponding compartments, $\alpha$ - microbial biomass fraction in organic soil layer, $\beta$ - humus fraction in organic soil layer.

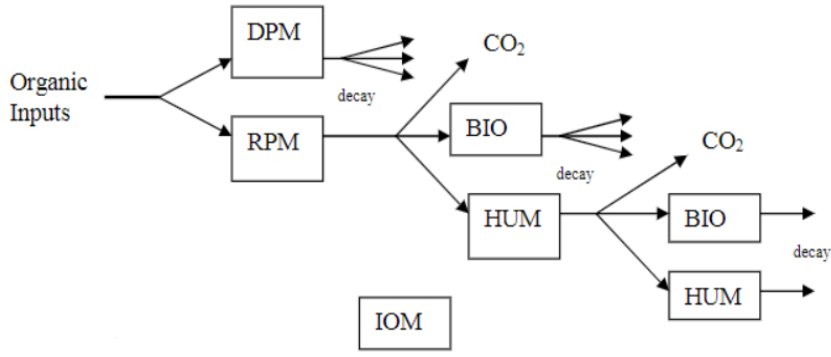

Fig. 4. Structure of ROTHAMSTED model

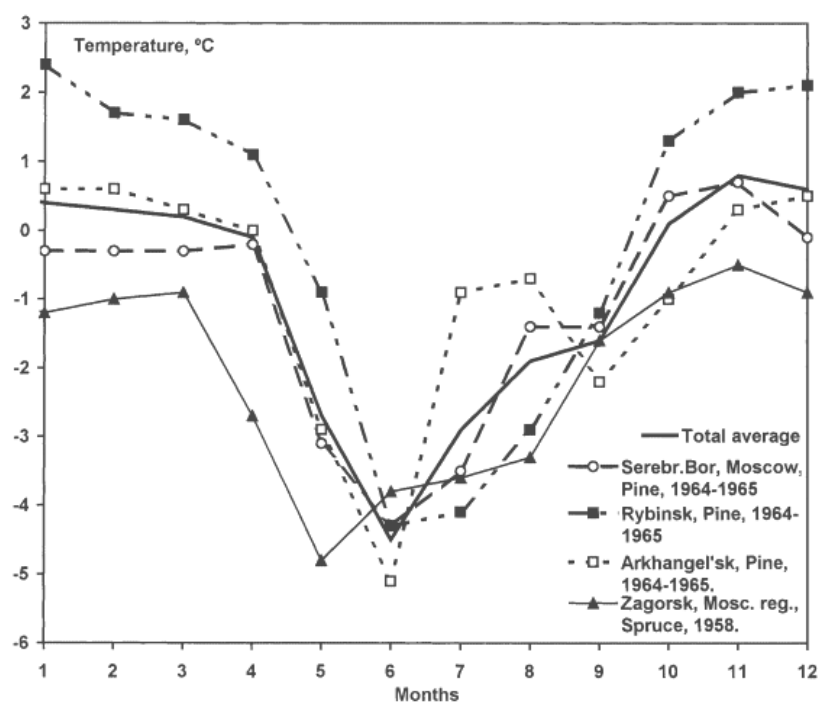

Fig. 5. The annual course of the difference between soil temperatures at the depth of $0.20 \mathrm{~m}$ under a forest and under a grass cover [2]

Quantity of carbon decomposed in each of the compartments is described by the exponential decomposition function:

$$
Y=Y_{0}\left(1-e^{-a b c k t}\right),
$$

where $Y_{0}$ - initial quantity of carbon, $a$ - rate modifying factor for temperature, $b$ - rate modifying factor for moisture, $c$ - soil cover rate modifying factor, $k-$ decomposition rate constant for that compartment, $t=\frac{1}{12}$ for a monthly period (since $k$ is based on a yearly decomposition rate).

The driving force of carbon loss from the soil is a microbial decomposition process that influences temperature and content of ground waters. The model adjusts for soil texture by altering the partitioning between $\mathrm{CO}_{2}$, microbial biomass and humified organic matter.
This ratio is calculated from the clay content of the soil using the following equation:

$$
x=1,67(1,85+1.6 \exp (-0,0786 g),
$$

where $g$ is the percent of clay in the soil.

Basing on the given model, we calculated the quantities of total organic carbon (TOC), particulate organic carbon (POC), humified organic matter (HUM) and inert organic matter (IOM) formed in the soil (Fig. 6).

Yearly organic matter contribution was calculated as a sum of carbon content in organic fertilizers and belowground crop biomass. The disadvantage of the model is that the model can only be used for arid climate territories and requires a considerable number of experimental data.

We also compared the quantity of carbon that will be formed in the soil in 10 years calculated using the models discussed above (Fig. 7).

We used the following initial model parameters for crust mor sandy surface-podzolic soil: initial nitrogen content in the organic soil layer -0.01689 , ash concentration in upper soil litter layer 0.523 , soil moisture and temperature data (Table 1). Based on the obtained results, we conclude that the process of carbon formation in the crust mor sandy surface-podzolic soil is modelled the most accurately by the Century model, as compared to the laboratory research

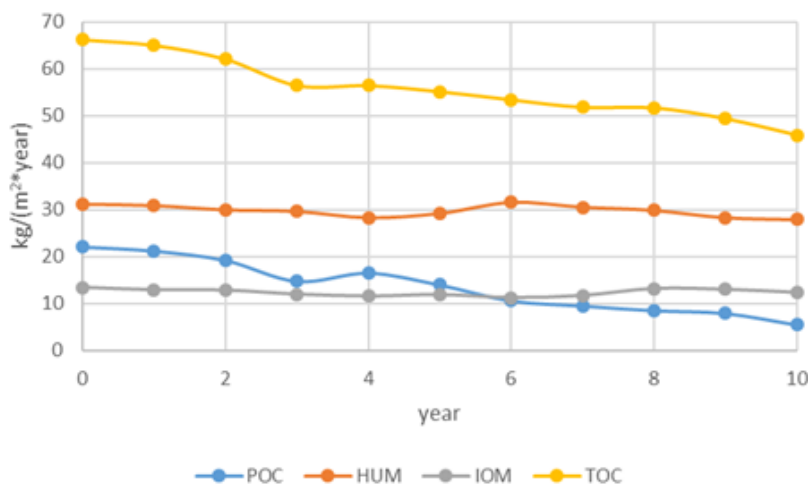

Fig. 6. The quantities of POC, HUM, IOM and TOC that will form in 10 years

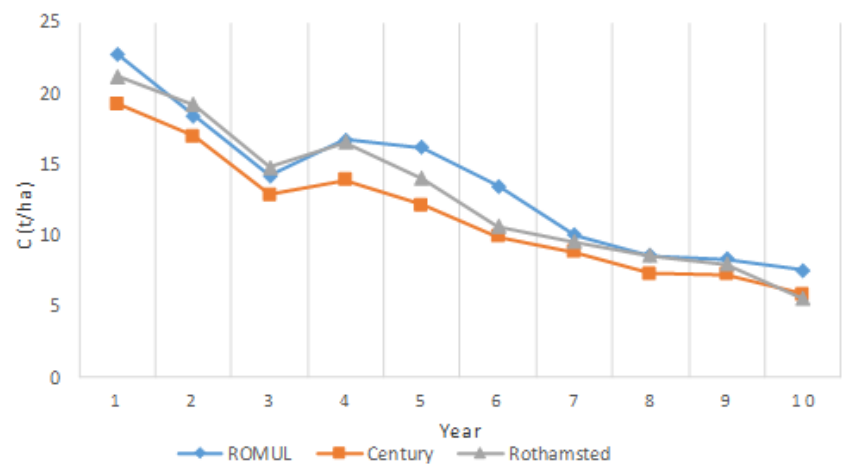

Fig. 7. Quantity of carbon that will be formed in the soil in 10 years, calculated with the ROMUL, Century and Rothamsted models

\section{Conclusion}

Using the meteorological database, we analysed and compared the results of the three dynamic soil organic matter formation models. The study suggests each model has its advantages and drawbacks. The common disadvantage of the models represented is a simplified representation of mineralization and humification processes. To improve these models, more attention should be payed to physico-chemical processes of humus formation, and the impact of soil granulometric composition on organic matter and nitrogen formation examined further. 


\section{References}

[1] Abtew, W.: Evapotranspiration measurements and modeling for three wetland systems in South Florida. Water Resour. Bull. 32(3)/1996, 465-473.

[2] Chertov O.G., Komarov A.S.: Immitational model of soil organic matter dynamics. Vestnik SPbGU Series 3 - Biology, 1/1996, 104-109 (in Russian).

[3] Chertov O.G., Komarov A.S.: Theoretical basis of modelling soil organic matter content dynamics. Pochvovedenie 8/2013, 937-946 (in Russian).

[4] Chertov O.G., Komarov A.S., Nadporozhskaya M. A.: Models of forest soil organic matter dynamics. Nauka, Moskow 2007 (in Russian).

[5] Chertov O.G., Komarov A.S., Nadporozhskaya M., Bykhovets S.S., Zudin S.L. ROMUL - a model of forest soil organic matter dynamics as a substantial too for forest ecosystem modeling. Ecological modelling 138 (1-3)/ 2001, 289-308.

\section{Liubov Shostak \\ e-mail: shostak_ak15@nuwm.edu.ua}

Liubov Shostak is a fourth year student of Applied Mathematics at the National University of Water and Environmental Engineering. She researches the problems of soil exhaustion by both natural conditions and human activity.

The work on the present paper is part of her diploma project entitled 'Modelling and evaluation of organic matter formation in the forests of Polesia'.

\section{ORCID ID: 0000-0002-7881-7366}

\section{M.Sc. Mykhailo Boiko}

e-mail: m.v.boiko@nuwm.edu.ua

Mykhailo Boiko is an assistant lecturer at the Department of Applied Mathematics, NUWEE. Recently graduated as a Master of Applied Mathematics, he has already been involved in a number of scientific projects concerning earth sciences, mathematical modelling, GIS and earth remote sensing.
[6] Jenkinson D.S., Hart P.B.S., Rayner J.H., Parry L.C.: Modelling the turnover of organic matter in long-term experiments at Rothamsted. Intecol Bull. 15/1987, $1-8$.

[7] Nadporozhkaya M.A.: Modelling of organic matter transformation in the soil (Ph.D. thesis). Saint-Petersburg State Agrarian University, Saint-Petersburg 2000 (in Russian)

[8] Nadporozhskaya M.A., Mohren G.M.J., Chertov O.G., Komarov A.S., Mikhailov A.V.: Soil organic matter dynamics at primary and secondary forest succession on sandy soils in The Netherlandsan application of soil organic matter model ROMUL. Ecol. Model. 190(3/4)/2006, 399-418 [DOI: 10.1016/j.ecolmodel.2005.03.025].

[9] Parton W.J., Stewart J.W.B., Cole C.V.: Dynamics of C, N, P and S in grasslands soils: a model. Biogeocemestry 5/1988, 109-113.

\section{Ph.D. Olha Stepanchenko \\ e-mail: o.m.stepanchenko@nuwm.edu.ua}

Olha Stepanchenko is an associate professor at the Department of Applied Mathematics, NUWEE Acquired her Ph.D. in Technical Sciences in 2013. Her research activities include work on a variety of topics, from mathematical modelling of natural processes to innovational methods in education processes.

Now Olha Stepanchenko leads the innovative department of NUWEE and manages the projects done by under- and postgraduate students.

ORCID ID: 0000-0001-6033-7404

\section{M.Sc. Olena Kozhushko}

e-mail:ol.d.kozhushko@nuwm.edu.ua

Olena Kozhushko is a junior research fellow at the National University of Water and Environmental Engineering. Her field of scientific interests concerns mathematical modelling of soil processes, including soil moisture and temperature modelling and numerical methods.
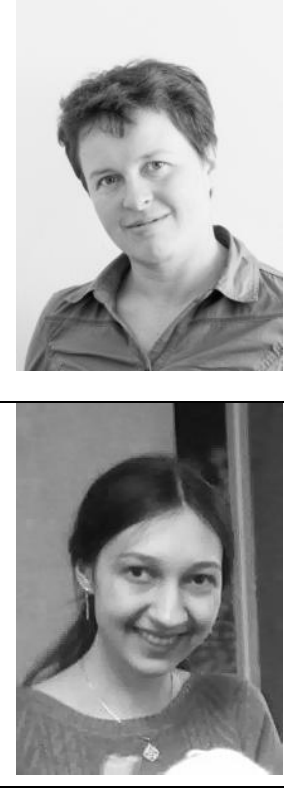